\title{
ARTITRS
}

Universidade de Marília,

MARIA INÊS ALMEIDA GODINHO

Marília, São Paulo, Brasil.

\section{O RURAL ATRAVÉS DE DOIS OLHARES NO FILME VIAJO PORQUE PRECISO, VOLTO PORQUE TE AMO}

\section{RESUMO}

Esta análise se detém sobre as representações do rural nordestino brasileiro no filme Viajo porque preciso, volto porque te amo, dos diretores Karim Aïnouz e Marcelo Gomes, lançado em 2009. Aqui partimos do pressuposto que uma obra cinematográfica, mesmo que resultante da visão subjetiva de seu narrador fílmico, ao ser entendida como um produto cultural de uma sociedade, também carrega em seu discurso representações dessa sociedade e de seu tempo histórico. Neste artigo, o exame dessas representações será realizado por meio da análise dos elementos significantes da linguagem cinematográfica (enquadramentos, iluminação, movimentos de câmera etc.) utilizados na construção da narrativa do filme em questão, já que acreditamos que é a partir da escolha

palavras-chave

Cinema; Rural; Representação; Linguagem; Decomposição fílmica. de cada elemento de linguagem que um filme pode revelar a seus espectadores as representações estéticas e ideológicas de determinado tempo social. 


\section{INTRODUÇãO}

Em 1999, Karim Aïnouz e Marcelo Gomes percorreram a região Nordeste do Brasil documentando suas paisagens e seus habitantes em diversos suportes e formatos audiovisuais (35mm, $16 \mathrm{~mm}$, Super-8, câmera digital e máquina fotográfica) para a produção do documentário Sertão acrílico azul piscina, lançado em 2004 para o projeto Itaú Cultural.

Anos depois reaproveitaram as imagens captadas e realizaram um novo filme, dessa vez um longa-metragem de ficção chamado Viajo porque preciso, volto porque te amo, lançado em 2009. Na falta de um personagem que conduzisse a trama, os diretores criaram um protagonista - o geólogo José Renato - e o inseriram na montagem, assim costurando ficcionalmente as imagens antigas. 0 espectador não pode ver José Renato, já que sua presença é criada através do recurso da voz off. Assim, as imagens do filme são as imagens vistas por José Renato ou captadas por ele.

No novo filme o geólogo sai de Fortaleza para uma viagem a trabalho ao interior do Nordeste. Sua função é avaliar tecnicamente o percurso de um canal aquífero que será construído para ligar a região de Xexéu (PE) ao Rio das Almas (BA). Nos trinta dias que dura a viagem, José Renato analisa a vegetação, o solo e as formações rochosas dos locais por onde o canal passará. Nas horas vagas registra também a vida dos habitantes. É justamente sobre os registros de José Renato, ou melhor, sobre os registros dos narradores cinematográficos - os diretores Karim Aïnouz e Marcelo Gomes - que esta análise se detém.

O cinema trabalha com representações, já que desde sua concepção um filme trata de escolhas, de pontos de vista, que organizam a percepção e reconstroem a realidade, "uma realidade estética que resulta da visão eminentemente subjetiva e pessoal do realizador" como afirma Betton (1987, 09). Assim, acreditamos que através do filme Viajo porque preciso, volto porque te amo podemos encontrar pistas sobre as representações de aspectos da vida rural do Nordeste brasileiro dos anos 2000. Partimos do pressuposto de que todos os filmes, sejam eles ficções ou documentários, carregam representações sociais do mundo histórico em que vive o narrador.

No filme, as representações do rural são construídas não somente através do verbal, ou seja, do conteúdo manifesto das falas dos atores, mas também através dos vários elementos de significação que constituem a linguagem cinematográfica, a exemplo dos planos, ângulos, movimentos de câmera, música, falas, ruídos, silêncio, iluminação, figuri-

1. Voz off - A indicação é utilizada quando existe um fluxo de pensamento, isto é, o personagem está refletindo ou sonhando, sem que ele faça parte da imagem. 
no, cenário e edição/montagem. De acordo com Citelli (1999, 26), para o estudo dos valores e ideias contidos em um discurso, seja ele qual for, deve-se observar a natureza dos signos que o constroem: "o modo de dispor o signo, a escolha de um ou outro recurso, revelaria múltiplos comprometimentos de cunho ideológico".

\section{PROCEDIMENTOS METODOLÓGICOS}

Para a análise dos elementos significantes da linguagem cinematográfica utilizados no filme aqui analisado, recorremos à metodologia sugerida por Penafria (2009): a denominada "análise da imagem e do som", que se concentra na decomposição do espaço fílmico em cada unidade de ação (o plano) e posterior análise da utilização desses vários elementos de significação da linguagem cinematográfica. Para a autora, a decomposição da narrativa cinematográfica recorre a conceitos "relativos à imagem (fazer uma descrição plástica dos planos no que diz respeito ao enquadramento, composição, ângulo, etc.), ao som (por exemplo, off e in) e à estrutura do filme (planos, cenas, sequências)".

Apesar de esse tipo de análise conter semelhanças com um estudo meramente estrutural, o método está, na verdade, atrelado a um exame de elementos externos ao filme: aqui o analista considera o filme como o resultado de um conjunto de relações, "nos quais decorreu a sua produção e realização, como sejam: o seu contexto social, cultural, político, econômico, estético e tecnológico" (Penafria, 2009, 07).

Como já dito, as representações não podem ser analisadas separadamente do tempo social em que são produzidas, pois as manifestações culturais de um país estão profundamente ligadas à dinâmica de sua sociedade, e, como tanto, têm a propriedade de possibilitar um questionamento sobre esse mesmo contexto histórico. Como confirma Hall $(2005,50)$, uma cultura nacional é um discurso - "um modo de construir sentidos que influencia e organiza tanto nossas ações quanto a concepção que temos de nós mesmos".

Portanto, é primordial relacionar a análise da imagem e do som sugerida por Manuela Penafria com uma avaliação do contexto social em que os filmes foram produzidos e veiculados. Nesse caso, analisamos, especialmente, a forma como o projeto de transposição do Rio São Francisco, empreendimento do Governo Federal iniciado em 2007 e nomeado como "Projeto de Integração do Rio São Francisco com Bacias Hidrográficas do Nordeste Setentrional", e que prevê a construção de mais de 700 quilômetros de canais de concreto em dois eixos (norte e leste) ao longo de quatro estados (Pernambuco, Paraíba, Ceará e Rio Grande do Norte), influencia a visão do narrador fílmico - no caso os diretores Karim Aïnouz 
e Marcelo Gomes - na construção das representações do rural nordestino brasileiro no filme viajo porque preciso, volto porque te amo.

\section{O NARRADOR EXTERNO E O NARRADOR INTERNO NA OBRA}

O filme começa com um longo plano geral de uma estrada à noite, a partir do ponto de vista de José Renato, que está dirigindo seu carro, sozinho. No rádio toca a música "Sonhos", de Peninha, um clássico da música brega que fala de um relacionamento fracassado, que, como saberemos mais adiante, é a mesma condição amorosa do geólogo, abandonado há algum tempo pela mulher que ama, a quem ele chama de Galega.

Já de dia, sempre a partir de seu ponto de vista e em imagens de baixa resolução, vemos o horizonte à frente, o céu carregado de nuvens e a paisagem árida ao lado da estrada. 0 enquadramento é fixo, apesar do movimento do carro e das motos e caminhões que trafegam pela estrada. Somente existe movimento fora da imobilidade de José Renato. Além de sua fala, os únicos sons são as músicas românticas que continuam a tocar no rádio do carro e os ruídos dos veículos, o que configura um trabalho de som diegético².

Essa estrutura audiovisual se repete em quase todo o filme, assim como as observações amargas de José Renato, que vai tecendo impressões para si mesmo ou, quem sabe, gravando suas observações para um superior - sobre seus instrumentos de trabalho, a geografia da região e, principalmente, sobre sua inadequação à viagem, a precariedade da região e a falta de perspectiva de seus habitantes.

Hoje é 28 de outubro, dia do funcionário público. Em Fortaleza ninguém trabalha na repartição, e eu aqui neste torrão seco dando um duro danado. [...] Mal comecei a viajar e tudo já me irrita. A paisagem não muda, é sempre a mesma coisa. Parece que não sai do lugar... [...] Que agonia este lugar. Tudo se arrasta... Saudade da porra... (Aïnouz e Gomes, 2009).

A utilização da câmera subjetiva ${ }^{3}$ para representar a visão do geólogo é o recurso narrativo que mais deixa pistas sobre o narrador fílmico. Ela leva o espectador a se colocar no lugar do narrador interno - José Renato - e, consequentemente, também leva ao ponto de vista do narrador externo, o cinematográfico.

2. Som diegético - todo som advindo de uma fonte sonora que é vista na imagem.

3. A câmera subjetiva - trata-se da câmera que se coloca no ponto de vista do personagem. 
À primeira vista a subjetividade pode remeter a uma característica recorrente entre as obras cinematográficas sobre o sertão produzidas a partir de 1995, período denominado Retomada, onde a região deixa de ser o cenário dos conflitos políticos e sociais do Cinema Novo para ser o lugar dos conflitos pessoais. Para Lúcia Nagib $(2000,116)$, os cineastas da Retomada - mais atraídos pelo exótico do que por sentimentos revolucionários - "concentravam-se obsessivamente sobre a individualidade dos personagens em detrimento do contexto social".

Como lembra Ismail Xavier $(2001,50)$,

parecia que o cinema agora caminhava mais leve, sem o peso de um projeto de intervenção ou transformação social, [...] sem aquele sentimento de urgência em que cada filme mostrava atrás da câmera um intelectual a diagnosticar o país no seu conjunto e a pensar por todos nós, pelos diferentes segmentos da sociedade.

Mas, em uma análise mais profunda, percebemos que a crítica social do filme não está na subjetividade de José Renato, ou seja, não está em seu olhar imóvel e sufocante direcionado a locais áridos e desocupados, e tampouco em suas falas tristes. É no mise-en-scène $e^{4}$ que a visão do narrador externo se revela, desmentindo a todo o momento a subjetividade de José Renato.

Logo na primeira pausa da viagem já encontramos as pistas deixadas pelo narrador fílmico: o geólogo está parado em frente a uma casa na beira da estrada, e a única coisa que se move é um pássaro que atravessa o enquadramento. Contrapondo essa construção melancólica do olhar do geólogo, o que se vê é um conjunto de casas simples em um céu azul límpido e uma brisa que remete a frescor e vida, indicativos que invalidam a ideia de um sertão abandonado e triste.

Segue-se a imagem fixa de dois moradores - "Seu" Nino e Dona Perpétua dentro da casa, ao lado de uma mesinha com imagens e fotografias de santos e algumas fotos de prováveis familiares, quase um altar da família. José Renato explica que eles serão os primeiros moradores a ser desapropriados, mas não há qualquer referência no filme sobre a causa dessa expropriação.

O plano longo, as falas entremeadas por longos silêncios, e, principalmente, o olhar fixo e tranquilo do casal dirigido ao geólogo mostra o respeito do narrador fílmico pela integridade da vida daquelas pessoas.

4. Mise-en-scène - de origem francesa, significa "colocado em cena". Tem sua origem no teatro clássico e se refere à movimentação e posicionamento dos atores no palco, bem como no set de filmagem; arte da encenação teatral ou cinematográfica. 
"Eles tão casados há mais de 50 anos... Nunca tiveram outra casa, nunca tiveram uma briga, nunca dormiram uma noite longe um do outro..." (Aïnouz e Gomes, 2009), diz José Renato.

Nesse mesmo plano, outro indicativo da visão do narrador fílmico sobre a vida rural é a presença de um receptor de rádio: "Seu Nino saiu pra desligar o rádio e eu pedi pra ele voltar... Não quis deixá-los separados" (Aïnouz e Gomes, 2009), diz José Renato.

Como lembra Lefebvre $(2001,19)$, assim como o carro e a televisão, o rádio é um elemento do sistema de objetos do "tecido urbano", isto é, do modo de viver da sociedade urbana que se entranha no meio rural. Na cena, ao ser desligado por Seu Nino, o objeto é retratado como se perturbasse o equilíbrio da vida no campo - como um símbolo da urbanização. Reforça essa impressão o destaque dado ao canto dos passarinhos em background (BG)5.

A situação de remoção vivida pela família de Seu Nino e Dona Perpétua remete imediatamente às consequências sociais do projeto de transposição do Rio São Francisco, que em alguns trechos deverá ter seu curso alterado através da construção de canais para irrigar locais do semiárido atingidos pela seca. o discurso do governo brasileiro é o de que será uma obra que levará desenvolvimento comercial às regiões atingidas pela transposição, mas como observam Oliveira e Rothman (2007, 213), "esquece-se de que há toda uma rede de relações sociais e antropológicas que serão fatalmente rompidas”.

No filme, os comentários técnicos de José Renato não incluem preocupações com a tensão social a ser gerada com a construção do canal:

É necessário um estudo mais profundo sobre a viabilidade econômica do canal nessa região. Deslocar torres de alta tensão em tantas estradas talvez seja inviável. Talvez o ideal seja procurar outra região como opção. [...] Por que insistem em fazer essa obra aqui? Na verdade não é problema meu" (Aïnouz e Gomes, 2009).

Mas percebe-se pela mise-en-scène que o narrador fílmico está preocupado com o custo social da remoção dos habitantes da região: o distanciamento de seu lugar de origem e a perda de sua cultura. É o que avalia Colito $(2000,283)$ quando analisa os impactos da construção da Usina Hidrelétrica de Jataizinho no Rio Tibagi (PR), que acreditamos serem os mesmos do projeto de transposição do Rio São Francisco:

5. Background - todo som que se sobrepõe a uma imagem ou a outro som. 
O espaço físico socialmente construído poderá perder as referências construídas através das relações estabelecidas no cotidiano de muitos anos, mas seus múltiplos significados não serão considerados pela avaliação tecnocrática. [...] As paisagens familiares deixarão de existir. Para alguns o grande lago representará "coisa nova" a ser explorada, mas para muitos, principalmente aqueles que formaram suas propriedades, significará perdas que não serão repostas (Colito, 2000, 283).

Outra sequência exemplar é a visita do geólogo à casa da família de Manuel Constantino, composta pelo casal e seus seis filhos. Os rapazes ajudam o pai na lavoura e as meninas auxiliam a mãe no cuidado da casa. José Renato comenta: "Não existe energia elétrica. A família vive em estado de isolamento extremo. Mas parecem felizes... Eu duvido desta felicidade" (Aïnouz e Gomes, 2009).

Mas o que a mise-en-scène apresenta é uma casa simples, porém grande, limpa e arejada, debaixo de um céu azul límpido. Todos os membros da família estão bem vestidos, e mesmo sem sorrir não esboçam desconforto tampouco ignorância, como se percebe pela filha com um livro na mão, motivo de um dos comentários amargos do próprio geólogo: "Uma delas lê e relê Dom Casmurro, de Machado de Assis” (Aïnouz e Gomes, 2009).

A maioria das imagens dessa sequência mostra os membros da família reunidos em grupos, também contrariando outra fala de Zé Renato: "Nessa viagem só vejo solidão na minha frente" (Aïnouz e Gomes, 2009).

Depois da visita à casa dos Constantino, o geólogo pega a estrada novamente, e no caminho se detém algumas vezes sobre detalhes do cotidiano local, como roupas no varal, um pai fazendo cócegas no filho, mãe e filha sentadas observando a estrada, um casal andando abraçado na beira da estrada. Tudo é registrado em planos longos, mas não arrastados como as imagens da estrada no início do filme.

Aqui a montagem lenta traduz o respeito do narrador externo pela forma com que essas pessoas apreendem sua existência: um ritmo de vida mais ligado ao tempo da natureza, mais contemplativo e menos estressante do que o ritmo de vida dos moradores das metrópoles. Essa nova construção audiovisual sugere a mescla entre os olhares dos dois narradores, o interno e externo, que agora se confundem.

Agora, José Renato também dirige seu olhar aos romeiros sorridentes, que acenam de caminhões enfeitados com imagens de santos, flores e bandeirinhas coloridas; e já escuta o ruído de alegres buzinas e da algazarra das crianças brincando ao entardecer. 
Já em Caruaru, cidade mais populosa do interior de Pernambuco, José Renato procura por um hotel, mas, de acordo com sua fala, um hotel "direito", com cama de casal, frigobar e ar condicionado: "porque não aguento mais pardieiro de beira de estrada" (Aïnouz e Gomes, 2009).

De acordo com Candido (1971, 165), essas necessidades materiais "contribuem para criar ou intensificar os vínculos com a vida das cidades". Apesar da afirmação do autor ser direcionada a seu estudo sobre os caipiras da região de Bofete (SP), acreditamos que a ideia possa ser estendida a esta análise, pois o recorrente olhar de José Renato a outros símbolos da urbanização, como caminhões, postos de gasolina e letreiros em neon, sugere sua intenção de reafirmar a todo o momento sua ligação com o mundo urbano.

Já de madrugada, desde a janela do quarto do hotel, José Renato observa a montagem de uma feira. o geólogo então abre seu coração, dando mais informações sobre sua desilusão amorosa e as saudades do passado com a Galega. É a partir desse ponto do filme que os enquadramentos duros e asfixiantes utilizados para caracterizar o olhar de José Renato tornam-se mais flexíveis: a câmera começa a se movimentar, acompanhando o movimento dos trabalhadores.

O som é trabalhado de forma a valorizar o burburinho da feira, com suas falas e risadas, e nas cenas seguintes também o tom da voz de José Renato vai se alegrando, principalmente quando fala sobre o café da manhã do hotel, sugerindo uma valorização de alimentos típicos do local: "O café da manhã era grátis. Incluía cuscuz, café com leite e suco de polpa de goiaba” (Aïnouz e Gomes, 2009).

Também se percebe um olhar mais carinhoso de José Renato a partir dessa sequência; um olhar construído por planos fechados ${ }^{6}$ que remetem a uma maior aproximação com as pessoas e as coisas do lugar, como detalhes de uma caixinha de música e as mãos de uma artesã recortando folhas de uma rosa de espuma sintética de cor forte. A proximidade é reforçada logo depois, quando uma menina que pede esmolas na beira da estrada é enquadrada em close $^{7}$ e José Renato compara seus olhos aos da Galega.

A inserção de elementos coloridos na mise-en-scène, a exemplo do fundo azul intenso que faz fundo para a menina e do colchão de palha forrado por um tecido florido que seca ao sol, também reforça a sugestão de uma provável quebra da resistência de José Renato em se inserir na vida do sertão.

\footnotetext{
6. Plano fechado - plano que enquadra alguém ou alguma coisa bem de perto.

7. Close - plano que enquadra somente o rosto do personagem, recurso enfático que privilegia expressões e sentimentos.
} 
Essa ideia é evidenciada quando José Renato começa a interagir com as pessoas que encontra pelo caminho, seja através dos sorrisos lançados direto ao geólogo - caso do pipoqueiro do circo e de um dos trabalhadores acampados na beira da estrada -, seja por meio de "entrevistas" que grava com o casal Carlos e Selma e com o senhor que fabrica os colchões de chita.

O fortalecimento do diálogo de José Renato com o sertão se percebe pela "entrevista" com Patrícia, primeiro momento do filme em que o protagonista se dirige diretamente a alguém. Pati é dançarina e garota de programa, e sua participação ganha destaque talvez porque ela deseje o mesmo que o geólogo - uma "vida-lazer": "uma vida-lazer é assim: eu na minha casa, eu e a minha filha, o companheiro que eu tiver ao meu lado, pra esquecer esses momentos todos porque não dá certo. É triste a pessoa gostar sem ser gostada" (Aïnouz e Gomes, 2009).

A presença de prostitutas na periferia das grandes cidades - caso de Pati, Larissa e de outras mulheres com quem o geólogo se relaciona é, de acordo com Candido (1971, 254), um dos efeitos da desintegração familiar provocada pelo movimento migratório das famílias pobres do interior para grandes cidades, como Caruaru, uma das mais populosas de Pernambuco.

Mas, no filme, a cidade de Caruaru também revela elementos de resistência cultural, como mostram as cenas em que Pati se diverte em um baile animado por um grupo musical regional composto de sanfoneiros e tocadores de triângulo. Entre os frequentadores está um casal que dança com um bebê no colo, indicativo da interação entre os habitantes da periferia.

Assim como o pequeno altar da casa de Seu Nino e Dona Perpétua, o baile é um dos elementos de preservação da cultura rural, que, como afirma Antônio Candido (1971, 202), "permitem resistir ao impacto da mudança [para a cidade] e atenuar seus efeitos desorganizadores".

Quase no final do filme, quando José Renato chega à garganta do Rio das Almas, na cidade de Piranhas, ponto inicial da transposição das águas, a imagem se torna mais definida, os barcos estão em movimento e o céu é de um azul intenso. 0 geólogo registra imagens de cadeiras na rua, da torre da igreja e de outros detalhes do lugar, como se quisesse guardar para si uma recordação da vida tranquila da cidade, que já teve a maior parte de seus moradores removidos.

É nesse lugar que José Renato assume o término de seu relacionamento amoroso, começa a desvincular-se da amargura e a valorizar antigas vivências cotidianas: "por isso fiz essa viagem: pra me mover, pra voltar 
a caminhar. Voltar a comer sanduíche de filé, voltar a andar de moto, voltar a ver o Fortaleza ganhar, pra voltar a ir à praia no domingo, pra voltar a viver" (Aïnouz e Gomes, 2009).

O momento é traduzido pela câmera em movimento que acompanha o geólogo subindo escadas rapidamente, revelando, provavelmente, seu desejo de se soltar das amarras da Galega. Quando chega ao fim da escadaria, que leva a um monumento, José Renato conta que sua vontade é mergulhar para a vida, com coragem, como fazem os saltadores de Acapulco.

As imagens que cobrem sua fala somente ilustram o relato: homens pulando de altos rochedos para mergulhar no mar. Se à primeira vista a metáfora pode parecer pobre, talvez signifique que José Renato não tenha quebrado totalmente sua resistência ao sertão, pois a referência à cidade mexicana e aos seus saltadores poderia indicar que o protagonista está ligado ao urbano de forma definitiva, já que Acapulco pode ser considerada um signo da urbanidade por ser um local turístico no exterior que, a princípio, é um destino exclusivo dos ricos moradores das cidades.

texto recebido

14.03 .2016

texto aprovado 21.09.2016

E, por extensão, talvez o narrador fílmico também esteja tentando dizer que, mesmo que o sertão esteja dentro da gente, como sentencia Riobaldo em Grande Sertão: Veredas, o mundo urbano vai, irreversivelmente, mergulhar e engolir as comunidades rurais de nosso País, como as águas engolem os saltadores de Acapulco e o Rio das Almas engolirá Piranhas.

\section{REFERÊNCIAS BIBLIOGRÁFICAS}

Aïnouz, Karim e Marcelo Gomes. 2009. Viajo porque preciso, volto porque te amo. Fortaleza, Ceará, Brasil, NTSC, cor, 75', DVD.

Candido, Antonio. 1971. Os parceiros do Rio Bonito: estudo sobre o caipira paulista e a transformação dos meios de vida. São Paulo: Duas Cidades.

Colito, Maria Clementino E. 2000. A construção de usinas hidrelétricas e os impactos sobre a população e o espaço - comunidades rurais ameaçadas pela $U$. $H$. de Jataizinho - Rio Tibagi /PR. Serviço Social em Revista, v. 2, n. 2, p. 275-258. Disponível em: <http://www.uel.br/revistas/ssrevista/n2v2.pdf>. Acesso em: 16 dez. 2015.

Betton, Gerard. 1987. Estética do cinema. São Paulo: Martins Fontes.

Citelli, Adilson. 1999. Linguagem e persuasão. 13. ed. São Paulo: Ática.

Hall, Stuart. 2005. A identidade cultural na pós-modernidade. Rio de Janeiro: DP\&A. 
Lefebvre, Henry. 2001. O direito à cidade. São Paulo: Centauro.

Nagib, Lúcia. 2000. O novo cinema sob o espectro do cinema novo. In: Estudos de cinema: Socine l e I/ / Socine, org. Socine. São Paulo: Annablume.

Oliveira, Douglas L. e Franklin D. Rothman. 2007. Desterritorialização de populações locais sob a ótica da justiça ambiental: abordagem dos conflitos do projeto de integração do Rio São Francisco. In: Seminário Nacional Movimentos Sociais, Participação e Democracia, 2., Florianópolis, 2007. Anais Florianópolis: UFSC.

Penafria, Manuela. 2009. Análise de filmes - conceitos e metodologia(s). VI Congresso SOPCOM. Abril de 2009. Disponível em: <http://www.bocc.uff.br/pag/boccpenafria-analise.pdf>. Acesso em: 12 jan. 2015.

Rosa, João Guimarães. 1994. Grande sertão: veredas. São Paulo: Nova Aguilar.

Xavier, Ismail. 2001. O cinema brasileiro moderno. São Paulo: Paz e Terra.

\section{MARIA INÊS ALMEIDA GODINHO}

Mestre em Comunicação Social pela Escola de Comunicação e Artes da Universidade de São Paulo. Docente na área de audiovisual e história da arte nos cursos de Publicidade, Arquitetura e Pedagogia da Universidade de Marília, São Paulo, Brasil. 